This item was submitted to Loughborough's Research Repository by the author.

Items in Figshare are protected by copyright, with all rights reserved, unless otherwise indicated.

\title{
Patterns of change in psychological variables leading up to competition in superior versus inferior performers
}

\section{PLEASE CITE THE PUBLISHED VERSION}

http://dx.doi.org/10.1123/jsep.2014-0216

\section{PUBLISHER}

(c) Human Kinetics Publishing as accepted for publication

\section{VERSION}

AM (Accepted Manuscript)

\section{PUBLISHER STATEMENT}

This work is made available according to the conditions of the Creative Commons Attribution-NonCommercialNoDerivatives 4.0 International (CC BY-NC-ND 4.0) licence. Full details of this licence are available at: https://creativecommons.org/licenses/by-nc-nd/4.0/

\section{LICENCE}

CC BY-NC-ND 4.0

\section{REPOSITORY RECORD}

Boat, Ruth, and lan M. Taylor. 2019. "Patterns of Change in Psychological Variables Leading up to Competition in Superior Versus Inferior Performers". figshare. https://hdl. handle.net/2134/20678. 
1

2

3

$4 \quad$ Patterns of change in psychological variables leading up to competition in superior versus 5 inferior performers

6

7

8

10

11

12

13

14

15

16

17

18

19

20

21

22

23

24

25
Manuscript Submitted: 21 ${ }^{\text {st }}$ August 2014

Manuscript Resubmitted: $6^{\text {th }}$ February 2015 
Abstract

27 The study explored patterns of change in a number of potentially performance-related

28

29

variables (i.e., fatigue, social support, self-efficacy, autonomous motivation, mental skills) during the lead up to a competitive triathlon, and whether these patterns of change differed for relatively superior versus inferior performers. Forty-two triathletes completed an inventory measuring the study variables every other day during a two-week period leading up to competition. Performance was assessed using participants' race time, and using a selfreferenced relative score compared to personal best times. Multilevel growth curve analyses revealed significant differences in growth trajectories over the two week period in mental skills use, social support, and fatigue. The results provide novel insight into how athletes' fluctuating psychological state in the two weeks prior to competition may be crucial in determining performance.

Keywords: Growth models, triathletes, sports performance 
Patterns of change in psychological variables leading up to competition in superior versus inferior performers.

Identifying factors that may influence sports performance is a primary goal for researchers and practitioners, and currently represents one of the most highly coveted areas of research and practice (Martindale, Collins, \& Daubney, 2005). However, a number of intrapersonal, interpersonal, and situational components can determine an athlete’s performance. Recognizing that the search for optimal performance requires a dynamic and multidimensional perspective will reflect the multilevel occurrences in humans when they compete. The extant literature has generally examined determinants of performance immediately prior to competition and paid little attention to how they unfold over time (Heazlewood \& Burke, 2011). To this end, the aim of the current research was to explore patterns of change in a number of potentially performance-related variables during the twoweek lead up to a competitive event. In addition, we explored whether the patterns of change differed for superior versus inferior performers.

Hardy, Jones, and Gould’s (1996) pyramid model of athletic performance describes a unifying framework which aids the understanding of the multiple factors that can impact athletic performance. The model posits that the foundations of peak performance are core motivational, personality, and philosophical foundations. While the latter two are unlikely to change in the lead up to an event, motivation may vary (Guay, Vallerand, \& Blanchard, 2000). From a self-determination theory (Ryan \& Deci, 2007) perspective, adaptive consequences are generally observed when motivation is autonomous, that is, when behavior originates from one's sense of self rather than driven by extrinsic contingencies (Ryan \& Deci, 2007). The few studies that have considered the link between motivation and sports performance have highlighted that autonomous motivation during training sessions is positively associated with subsequent performance (e.g., Gillet, Vallerand, \& Rosnet, 2009); 
however, this conclusion has not always been substantiated (Nezhad \& Sani, 2012). This research has predominantly evaluated athletes’ performance using subjective perceptions provided by coaches, and has assessed motivation at the contextual level (i.e., relatively stable motivation towards a specific domain; Gillet et al., 2009). Therefore, it would be interesting to examine changes over time in autonomous motivation at a situational level and utilize an objective measure of athletes’ performance.

A second motivational cognition that may be associated with ideal performance states is self-efficacy (Krane \& Williams, 2006), which can be described as a person’s perception of their ability to perform successfully in a specific activity (Bandura, 1997). Self-efficacy stimulates effort towards an activity and the amount of persistence one exhibits in the face of failure or adversity (Bandura, 1997). Unsurprisingly, therefore, self-efficacy has been consistently and positively related to athletic performance (e.g., Gilson, Chow, \& Feltz, 2012). However, the strength of the relationship between self-efficacy and sports performance was often weaker than expected. Research is warranted, therefore, to examine whether the influence of self-efficacy on sports performance changes over time, and whether such patterns of change differ for superior versus inferior performers. For example, it is possible that less successful performers experience a steeper decline in self-efficacy as competition approaches, compared to successful performers.

Hardy et al’s (1996) pyramid model proposes that core motivational foundations must be supplemented with appropriate psychological skills and adversity-coping strategies. Guided imagery, goal setting, and arousal control, to name a few, can be utilized during training and competition to control one's emotional and cognitive processes with the anticipation of actualizing the ideal performance state. Although sport psychologists have adopted these techniques for decades, alternative perspectives have reported that efforts to control, eliminate, or supress internal thoughts may have the opposite effect (Schwanhausser, 
2009). It has been argued that many of the interventions in applied sport psychology which teach mental skills techniques are based upon unverified hypotheses, rather than on scientific evidence (Morgan, 1997; Robazza, Pellizzari, \& Hanin, 2004). Therefore, research is required to determine the role mental skills techniques may play in influencing objective sports performance.

In addition to psychological skills, adversity-coping strategies are theorized to be critical to the development of successful performances (Hardy et al., 1996). Social support has been increasingly identified as such a valuable strategy (Freeman \& Rees, 2009), yet has received little attention within the sports performance literature (Harmison, 2011). Highachieving sports people require support with everyday issues and sport-specific demands, including concerns surrounding competition (Freeman, Coffee, \& Rees, 2011). This support may result in the benign appraisal of stressful events, or an assignment of resources leading to greater coping (Freeman et al., 2011), which may lead to greater performance. Moreover, superior performers may experience robust and stable social support networks in the lead up to competition, compared to inferior performers. Therefore, it would be interesting to examine whether the influence of social support changes during the pre-competition period. For instance, superior performers may potentially experience a steeper incline in social support as competition approaches compared to less superior performers.

In addition to appropriate cognitions, the ideal performance state is also influenced by physiological parameters (Hardy et al., 1996). An inevitable characteristic during the career of any athlete is physiological fatigue, constituting symptoms of tiredness which advance when athletes endure high volume training (Derman et al., 1997). Failure to adequately recover from training can produce a state of fatigue which leads to a decline in athletic performance (Mujika, 2011). From a psychological perspective, the perception of fatigue may limit performance, as well as the actual capability of the skeletal muscles (Marcora, 
2009). This proposal has been tested utilizing simulated sport protocols exploring components of performance (e.g., speed); however, research is required to assess perceptions of fatigue in the build up to actual sports performance.

Hardy et al's (1996) framework and the reviewed research implies that a multitude of psychological factors influence athletic performance. Much of the existing evidence, however, has assessed athletic performance using subjective outcomes such as evaluation by coach or on self-perceptions of performance, leading to conflicting and inconsistent findings that lack implications for objective performance. In addition, many of the potential performance determinants discussed may vary over time, which emphasizes the importance of examining athletes' responses during the lead up to a competitive event through a process oriented (i.e., change-over-time) research design. The few investigations on such a theme have looked at pre-competition periods of 24 and 48 hours (e.g., Wiggins, 1998; Swain \& Jones, 1993). When using a somewhat limited pre-event phase, however, performance influences have remained stable during the time leading up to the event. As such, the exploration of a larger pre-competition period could allow a more comprehensive insight into the changes that may occur as athletes near competition (Wiggins, 1998), and whether the rate of change is different for superior and inferior performers.

In sum, the aim of the current research was to explore whether a number of variables that have the potential to influence sports performance change during the two-week period leading up to competition. A two-week period allowed for interesting patterns of growth to be identified while not overburdening participants and reducing the quality of the data. Based on relevant components of Hardy et al's (1996) model of athletic performance, the study variables included autonomous motivation, self-efficacy, mental skills use, social support, and perceptions of fatigue. We also explored whether the patterns of change in the study variables differed for superior versus inferior performers. 
In accordance with the literature considered above, it was hypothesized that all variables would show some degree of change over the two-week period; however, specific rates of change were not hypothesized. It was also expected that athletes who performed successfully would report higher levels of self-efficacy, social support, mental skills use, and autonomous motivation, in addition to lower levels of perceptions of fatigue, compared to less successful performers. Finally, it was speculated that differences in the study variables between high and low performers would be particularly seen nearer to the competitive event.

\section{Method}

\section{Participants and Procedures}

Participants comprised 42 athletes (30 male, 12 female; $M$ age $=29.6$ years, $S D=7.1$, range 22-51), who competed in an Olympic distance triathlon (1.5 kilometres swim, 40 kilometres bike, 10 kilometres run) between June and August 2013. The participants had, on average, 2.4 years $(S D=3.4)$ competitive experience in their sport and spent $8.3(S D=3.5)$ hours per week training. Participants represented competitive recreational athletes; therefore, these athletes were not paid to compete and they do not represent elite level athletes.

Ethical approval was obtained from a university ethics committee, and the study was conducted according to APA guidelines. Prospective athletes were recruited through a local open water swimming venue, and provided with information outlining the purpose and procedures of the research. Athletes under the age of 18 were not allowed to participate and participants were informed that their involvement was anonymous and voluntary. First, participants were instructed to complete an informed consent form and record their personal best race time (in minutes) that they had accomplished in an Olympic distance triathlon. Two-weeks prior to their next triathlon, participants completed an inventory measuring the study variables (with the exception of performance) and were instructed to complete the same questions every other day during the two-weeks leading up to their competitive triathlon, with 
the final measure being completed on the morning of the competition. All participants completed the inventory on eight separate occasions and questions took approximately five minutes to complete each time. Finally, participants’ performance time was recorded on completion of the triathlon; this was obtained from the official records provided by the race organizers in one of six triathlons.

\section{Measures}

Performance. Performance was measured in two ways. Normative performance was assessed using participants’ time (in minutes) obtained from the official records provided by the race organizers. As an indicator of individuals' self-referenced performance, the difference in performance time compared to their personal best was converted into a percentage score. For example, a score of -11 meant that the participant had performed 11 percent better than their previous best, and a score of 13 indicated that the participant had performed 13 percent worse than their previous best.

Autonomous motivation. Autonomous motivation was assessed using two items from the Situational Motivation Scale (SIMS; Guay et al., 2000) alongside one item from the Behavioural Regulation in Sport Questionnaire (BRSQ; Lonsdale, Hodge, \& Rose, 2008). This was because the SIMS does not measure integrated regulation, which is an important facet of autonomous motivation (Ryan \& Deci, 2007). The items were "Because I think that training is interesting”, "Because I am doing it for my own good”, and "Because what I do in training is an expression of who I am”. These items were selected from the SIMS and BRSQ as they had the highest factor loadings onto their respective latent factor and acceptable reliability in original validation work (Guay et al., 2000 \& Lonsdale et al., 2008). Athletes indicated the reasons for which they were currently training for their triathlon on a sevenpoint scale ranging from 1 (corresponds not at all) to 7 (corresponds exactly). 
Self-efficacy. Self-efficacy was measured using two items from the self-confidence subscale of the Competitive State Anxiety Inventory-2 (Martens, Vealey, Burton, Bump, \& Smith, 1990). These items were chosen from the original instrument as they had acceptable factor loadings and reliability in a previous validation study (Martens et al., 1990) and were deemed to have good face validity. Participants were asked to reflect on how they felt about their upcoming triathlon (e.g., "I feel confident I can meet the challenge” and "I feel selfconfident”) on a four-point scale anchored by 1 (not at all) to 4 (very much so).

Mental skills use. Athletes' use of mental skills during training was assessed using the practice subscale of the Test of Performance Strategies (TOPS; Thomas, Murphy, \& Hardy, 1999). One item each from the self-talk ("I motivate myself to train through positive self-talk"), emotional control ("I have trouble controlling emotions when things are not going well”), automaticity (“I am able to perform skills without consciously thinking”), goal setting (“I set very specific training goals”), imagery ("When I visualise my performance, I imagine what it will feel like”), activation (“In training, I can get my intensity levels just right”), relaxation (“I use relaxation techniques to improve my performance”), and attentional control (“I am able to control distracting thoughts when training”) subscales were used. Participants were asked to indicate how frequently each item applied to them in the last couple of days ranging from 1 (never) to 5 (always). These items were selected from the TOPS as they had the highest factor loadings on their respective factor and acceptable reliability in previous validation work (Thomas et al., 1999).

Social support. Athletes’ perceived social support was assessed using items from the Perceived Available Support in Sport Questionnaire (Freeman et al., 2011). One item each from the emotional support (“To what extent would someone care for you”), esteem support (“To what extent would someone boost your sense of competence”), informational support ("To what extent would someone give you advice about performing in your competition"), 
and tangible support (“To what extent would someone do things for you at competition”) subscales were used. Participants were asked to indicate how they currently felt about each item ranging from 1 (not at all) to 4 (very much so). These items were chosen from the original instrument as they had acceptable factor loadings on their respective latent factor and reliability in original validation work (Freeman et al., 2011), and were deemed to have good face validity.

Perceptions of fatigue. Fatigue was assessed using the fatigue subscale from the Profile of Mood States (POMS; McNair, Lorr, \& Droppleman, 1992; i.e., "I feel physically worn out" and "I feel physically exhausted”). Participants were instructed to consider the degree to which they were currently experiencing the items on a five-point scale anchored by 1 (not at all true) to 5 (very true). These items were selected from the POMS as they had the highest factor loadings in previous research and acceptable reliability (e.g., Beedie, Terry, \& Lane, 2000).

\section{Data Analysis}

Study hypotheses were investigated using multilevel growth models employing MLwiN 2.26 software (Rasbash, Steele, Browne, \& Goldstein, 2012). Two levels of analysis were specified. Level 1 constituted the repeated observations of the study variables, which were nested within triathletes, who comprised Level 2 in the analysis. Therefore, the sample size at Level 1 was 336 (42 participants over eight time waves). The first part of the analysis examined whether the study variables significantly changed over the two-week precompetition period. This was achieved by including in a step wise fashion, linear, quadratic, and cubic effects of time as predictors of each variable (one unconditional growth model was constructed for each psychological variable). Time was centred on the morning of competition (i.e., the morning of competition was labelled zero, with increasing values the further from competition), therefore, the intercept represented the average score for the 
variable on the morning of competition and the slopes for time represented the rate of change in the study variable. The intercept and slope coefficients were explored as random effects to establish the extent of between-person variation in the intercepts and rates of change of all psychological variables under investigation (i.e., Do triathletes differ in their scores and rate of change in scores?).

The second part of the analysis aimed to ascertain whether any between-person variation in the intercept or slope parameters found in the first step could be accounted for by the two performance-based predictors (i.e., Do high and low performers differ in their scores and rate of change?). Specifically, the normative performance variable was added to the unconditional growth models as a main effect, which established whether the relevant psychological variable on the morning of competition differed across high and low performers. Normative performance $\times$ time interaction terms were also included in the models to establish whether the study variables changed over the two-week period differently for high performers and low performers. To maintain parsimony, only significant predictors of the intercepts or slopes (or associated between-person variance) were retained in the final models presented. These models were then repeated with the self-referenced performance variable replacing normative performance.

\section{Results}

\section{Preliminary analysis}

Table 1 displays intraclass correlation coefficients for all study variables, descriptive statistics for each of the eight measurement occasions, as well as median Cronbach's alpha coefficients for all study variables. Cronbach's alpha coefficients revealed that all subscales demonstrated adequate scale score reliability. Intraclass correlation coefficients ranged from .47 to .88 , indicating that between 12 and 53 percent of the variance in the study variables were attributable to the within-person level. 


\section{Primary analysis (see Table 2 and Table 3)}

Autonomous motivation. The first part of the analysis indicated significant cubic effects of time. Autonomous motivation decreased slightly two weeks before competition, followed by a slight increase as the athletes prepared to compete, and finally a decrease in the days prior to competition. No between-person variation in growth parameters was observed. Note that in this model, and all subsequent growth models, modeling the between-person variance of the cubic growth parameter could not be estimated due to nonconvergence of the models. However, the between-person variance of the intercept term was significant, indicating that autonomous motivation on the morning of competition varied across participants. Inclusion of either performance variable as a predictor of the intercept revealed that no differences existed in autonomous motivation between successful and non-successful performers on the morning of the competition. Furthermore, non-significant performance $\times$ time interactions suggested no differences in the patterns of change in autonomous motivation across high versus low performers. See Figure 1a for a visual representation of the rate of change in autonomous motivation.

Self-efficacy. The first part of the analysis indicated significant cubic effects of time. Self-efficacy decreased slightly two weeks before competition, followed by a slight increase as athletes get ready to compete, and finally a decrease leading up to competition. The between-person variance of the linear and quadratic growth parameters was statistically significant, meaning that the rate of change differed across individuals. Also, the betweenperson variance of the intercept term was significant, suggesting that self-efficacy on the morning of competition varied across participants. Inclusion of either performance variable as a predictor of the intercept revealed that no differences existed in self-efficacy between successful and non-successful performers on the morning of the competition. Furthermore, non-significant performance $\times$ time interactions suggested no differences in the patterns of 
change in self-efficacy across high versus low performers. See Figure $1 \mathrm{~b}$ for a visual representation of the rate of change in self-efficacy.

Mental skills use. The first part of the analysis indicated significant cubic effects of time. No between-person variance in growth parameters was observed. The between-person variance of the intercept term was significant, meaning that mental skills use on the morning of competition varied across participants. Inclusion of the self-referenced performance variable as a predictor of the intercept indicated that successful performers reported higher levels of mental skills use compared to less successful performers on the morning of competition. Non-significant performance $\times$ time interactions suggested no differences in the patterns of change in mental skills use across high versus low performers (using selfreferenced criteria; Figure 1c). Utilizing the normative performance variable, no differences were observed on the morning of the competition. However, a significant performance $\times$ linear time interaction was observed, which indicated worse performers’ mental skills use increased more during the two-weeks leading up to competition, compared to better performers (Figure 2a).

Social support. The first part of the analysis revealed significant cubic effects of time. Furthermore, significant between-person variance in the linear growth parameter was observed. The between-person variance of the intercept term was significant, meaning that social support on the morning of competition varied across participants. Inclusion of the selfreferenced performance variable as a predictor of the intercept revealed that higher performers reported higher levels of social support compared to low performers on the morning of competition. Furthermore, significant self-referenced performance $\times$ linear time interactions indicated that the difference in social support across high and low performers grew larger as the competition drew closer (Figure 1d). Inclusion of the normative performance variable revealed no differences on the morning of competition but a significant 
performance $\times$ linear time interaction. This suggested that differences between better and worse performers' social support tended to manifest as the competition drew closer (with worse performers reporting higher social support; Figure 2b).

Perceptions of fatigue. The first part of the analysis revealed that perceptions of fatigue did not significantly change over the pre-competition period. However, significant between-person variation in the linear and quadratic growth parameters was observed. Furthermore, the between-person variance of the intercept term was significant, meaning that perceptions of fatigue on the morning of competition varied across participants. Inclusion of the self-referenced performance variable as a predictor of the intercept indicated that no differences occurred between successful and non-successful performers on the morning of the competition. Nonetheless, a significant self-referenced performance $\times$ quadratic time interaction suggested that better performers’ perceptions of fatigue slightly increased between 14 and eight days to competition, before decreasing during the lead up to competition. In contrast, low performers’ perceptions of fatigue decreased to a small degree and relatively linearly during the lead up to competition (Figure 1e). Inclusion of the normative performance variable revealed no differences on the morning of competition. However, a significant performance $\times$ linear time interaction indicated that better performers' perceptions of fatigue decreased more compared to worse performers (Figure 2c). Figure 2c also suggests clear differences between the high and low performers at the beginning of the study (high performing athletes are more fatigued two weeks from competition).

\section{Discussion}

Given that the identification of factors that may influence sports performance is a fundamental objective for researchers and practitioners, and that the extant literature has largely examined determinants of performance immediately prior to competition, it is important to understand how the potential determinants of successful performance unfold 
over time. In this study we extended previous performance research by examining changes in a number of variables that have the potential to influence sports performance during the twoweek period leading up to competition. In addition, we explored whether the patterns of change differed for superior versus inferior performers. The results lent some support to the study hypotheses; all variables did demonstrate some degree of change over the two-week pre-competition period and differences existed between superior and inferior performers in some of the study variables.

Consonant with our predictions, autonomous motivation significantly changed during the pre-competition period, supporting the notion that external events can change ones situational intrinsic motivation for a given activity. Autonomous motivation decreased slightly two weeks before competition, followed by a slight increase as the athletes prepared to compete, and finally a decrease in the days prior to competition. These changes in autonomous motivation did not differ for superior versus inferior performers nor were differences observed on the morning of competition, contradicting previous research (Gillet et al., 2009). Rather, the findings provide support for Nezhad and Sani’s (2012) recent conclusions that self-determined motivation during training did not predict subsequent competitive performance. The fact that we, and other researchers, have investigated the independent influences of particular types of motivation (i.e., just autonomous motivation) may explain these equivocal findings. Instead, it may be beneficial for motivational profiles to be considered, such as a combination of high autonomous and certain controlling motives, and how these relate to sports performance. Research with elite track and field athletes and recreational athletes suggests that a motivational profile containing high self-determined and non-self-determined motivation may lead to successful sports performance (Mallett \& Hanrahan, 2004; Vlachopoulos, Karageorghis, \& Terry, 2000). 
Similar to autonomous motivation, self-efficacy significantly changed over the two-

374

375

weeks leading up to competition. Self-efficacy decreased slightly two weeks before competition, followed by a slight increase as athletes get ready to compete, and finally a decrease leading up to competition. This supports the notion that efficacy beliefs can be altered by intervening experiences (Bandura, 1997). However, the rates of change in selfefficacy did not differ for superior versus inferior performers, nor were there differences on the morning of competition. These findings contradict existing literature that indicates positive and significant correlations between self-efficacy and subsequent performance in a number of sports (Ede, Hwang, \& Feltz, 2011). The concordance between the self-efficacy and performance measures may explain such results. As we were interested in measuring race time as our performance measure, then it may have been advantageous for the selfefficacy measure to ask participants how confident they are that they will perform a personal best time, opposed to general self-efficacy statements. The use of concordant measures may have resulted in significant relationships between self-efficacy and performance emerging during the lead up to competition. Alternatively, it may be possible that self-efficacy is not important for sports performance or may only be indirectly related to performance through performance-related mediators.

Our results demonstrated that those who performed well (compared to self-referenced criteria, but not normative criteria) reported higher mental skills use on the morning of competition, compared to those individuals who performed inferiorly. Our results parallel those presented by Thelwell, Greenlees, and Weston (2006), who reported that individuals using mental skills prior to competition were more likely to perform successfully on a number of performance subcomponents assessed during competitive soccer matches. However, the benefits of mental skills may not be so definitive when considering normative performance. Worse performing triathletes increased their use of mental skills over the two- 
week period of the study, whereas better performing triathletes did not. More consistent mental skills use rather than suddenly applying mental skills as competition nears may help to avoid detrimental performance that may result from utilizing unfamiliar techniques during competition (Gould, Dieffenbach, \& Moffett, 2002).

This different pattern of mental skills use and associations with normative performance and self-referenced performance may suggest that these self-regulatory processes may serve different functions. If a poor performance relative to normative standards was expected during the lead up to competition (as is often the case) then mental skills can be used to maintain investment in the triathlon (e.g., through goal setting and positive imagery). Superior normative performers may not require mental skills to maintain invested in the lead up to competition. On the flip side, mental skills may help to improve one’s own (i.e., self-references) performance because of the performance enhancement properties of mental skill use.

Significant changes and differences over time were observed for social support.

Those individuals performing superiorly (using self-referenced criteria) had higher levels of social support on the morning of competition, compared to those performing inferiorly. In addition, this difference in social support grew larger as the competition drew closer. This finding is in accordance with results of previous research implying that social support represents a valuable component in actual sports performance (Freeman \& Rees, 2009). Surprisingly, however, consideration of normative performance did not convey supporting results. Differences in social support between successful and unsuccessful performers tended to emerge as competition neared, with unsuccessful performers reporting higher social support. As triathlon is an individual sport, it could be that successful performers do not require the large social support resources that are found in other sports (i.e., team sports). Successful performers may experience robust and stable social support networks during 
regular training sessions to help with everyday issues and sport-specific demands; however, once competition approaches it becomes an individual challenge where successful performers require less social support. Findings from this study provide new insights into the importance of social support for self-referenced performance, but not normative performance. It is possible that the type of performance measure utilized in research on social support and sports performance could explain such inconsistent findings.

Last, differences existed in the patterns of change in perceptions of fatigue across high versus low performers, supporting the conception that the perception of fatigue may limit performance (Marcora, 2009). When considering normative performance, the decline in fatigue during the lead up to competition tended to be greater for successful performers. The graphical representation of change also implied that high performers are more fatigued two weeks prior to performance, compared to less successful performers. These differences and patterns likely reflect a typical training schedule of successful triathletes during the lead up to a competitive event (i.e., intense training followed by a significant reduction in the lead up to an event). A similar, but less marked pattern of fatigue was also demonstrated in successful triathletes using self-referenced performance criteria. The psychological perception of fatigue during the lead up to competition is a major factor in successful athletic performance (e.g., Marcora, 2009). The patterns observed in our findings seem to suggest that better performers are more successful in managing psychological aspects of fatigue during competition preparation. This is particularly interesting given that perceptions of fatigue did not differ on the morning of competition across successful and unsuccessful performers.

Therefore, it may be the perception of declining fatigue that is important for sports performance, rather than actual levels of fatigue (notwithstanding extreme levels of fatigue). Taken together, findings convey that a number of performance-related variables change during the two-week period leading up to competition and these patterns may 
influence both self-referenced and normative performance. However, our motivational

variables (autonomous motivation and self-efficacy) were less influential in sports the appropriate psychological skills and adversity coping strategies during training that will prepare them to enter a competition in an ideal performance state. For example, it is possible that the proximal antecedents of Hardy et al's (1996) model (mental skills and fatigue) are more important for actual sports performance than the distal antecedents (motivation and selfefficacy). Overall, athletes may report a similar psychological state on the morning of competition, but the preceding two weeks may be a crucial period in determining performance level.

The change-over-time data further reiterates the importance of process orientated immediately prior to performance, it may not be considered an influential factor for superior athletic performance. The undertaking of further temporal based research could be instrumental to the applied sport psychologist concerning interventions for athletes (Hanton, Thomas, \& Maynard, 2004) and the researcher developing models of human performance.

\section{Limitations and Future Directions}

Further exploration of the variability of the study variables across different talent levels is warranted. For example, do determinants of performance differ as a function of competitive experience or level of expertise? It is also important to consider that every race may not be a priority race for recreational athletes; therefore, individuals’ goals and expectations may vary. It could be argued, however, that recreational triathletes compete in

471 less triathlons in a season, therefore, having different levels of expectation would be less

472 likely. Also, some key issues related to the sport of triathlon may need consideration, for 
instance, each triathlon venue may include unique features (e.g., different terrain and varying levels of elevation) that could influence performance to some degree.

A further limitation of this study was that only a relatively small sample of athletes competing in Olympic distance triathlons were assessed, therefore, future research should attempt to corroborate the findings in other sports and with larger samples to enhance the generalizability of the findings. In addition, original response scales were maintained in the present study, however, it is typical to extend response scales in diary studies or replace them with visual analog scales to provide more sensitivity to detect temporal fluctuations in ratings (McCormack, Horne, \& Sheather, 1988).

Finally, the methodology used provides researchers with greater temporal insight into changes in performance variables than cross-sectional designs allow. However, longitudinal research assessing multiple performances would be beneficial to further confirm our findings. Moreover, further examination of Hardy et al's (1996) model of athletic performance is required. While Hardy and colleagues state that all aspects of this model need to be considered for a complete understanding of athletic performance, it is possible that specific antecedents of the model are more important for task-specific ideal performance states. For instance, the proximal antecedents may be more important for sports performance than the distal antecedents or specific antecedents of the model become more or less important as competition draws closer.

\section{Conclusion}

The present study represents the primary attempt to examine changes in a number of variables that have the potential to influence sports performance during the two-week period leading up to competition, and explore whether the patterns of change differed for superior versus inferior performers. The key implication of the present research is to ensure that researchers and practitioners recognize that athletes may report a similar psychological state 
on the morning of competition, but the preceding two weeks may be a crucial period in determining performance level.

\section{References}

Bandura, A. (1977). Self-efficacy: The exercise of control. New York, NY: Freeman.

Beedie, C. J., Terry, P. C., \& Lane, A. M. (2000). The profile of mood states and athletic performance: Two meta-analyses. Journal of Applied Sport Psychology, 12, 49-68.

Derman, W., Schwellnus, M. P., Lambert, M. I., Emms, M., Sinclair-Smith, C., Kirby, P., \& Noakes, T. D. (1997). The 'worn-out athlete': A clinical approach to chronic fatigue in athletes. Journal of Sports Sciences, 15, 341-351. doi:10.1080/026404197367353

Ede, A., Hwang, S., \& Feltz, D. (2011). Current directions in self-efficacy research in sport. Magazine of Latin American Psychology of Exercise and Sport, 6, 181-201.

Freeman, P., Coffee, P., \& Rees, T. (2011). The PASS-Q: The perceived available support in sport questionnaire. Journal of Sport and Exercise Psychology, 33, 54-74.

Freeman, P., \& Rees, T. (2009). How does perceived support lead to better performance? An examination of potential mechanisms. Journal of Applied Sport Psychology, 21, 429-441. doi:10.1080/10413200903222913

Gillet, N., Vallerand, R. J., \& Rosnet, E. (2009). Motivational clusters and performance in a real-life setting. Motivation and Emotion, 33, 49-62. doi:10.1007/s11031-0089115-z

Gilson, T. A., Chow, G. M., \& Feltz, D. L. (2012). Self-efficacy and athletic squat performance: Positive or negative influences at the within and between levels of analysis? Journal of Applied Social Psychology, 42, 1467-1485. doi:10.1111/j.1559-1816.2012.00908.x

Gould, D., \& Dieffenbach, K., \& Moffett, A. (2002). Psychological characteristics and their development in Olympic champions. Journal of Applied Sport Psychology, 

14, 172-204. doi:10.1080/10413200290103482

Guay, F., Vallerand, R. J., \& Blanchard, C. (2000). On the assessment of situational intrinsic and extrinsic motivation: The Situational Motivation Scale (SIMS). Motivation and Emotion, 24, 175-213. doi:10.1023/A:1005614228250

Hanton, S., Thomas, O., \& Maynard, I. (2004). Competitive anxiety responses in the week leading up to competition: The role of intensity, direction and frequency dimensions. Psychology of Sport and Exercise, 5, 169-181. doi:10.1016/S1469-0292(02)00042-0

Hardy, L., Jones, G., \& Gould, D. (1996). A unifying model of psychological preparation for peak athletic performance. In Understanding psychological preparation for sport: Theory and practice of elite performers (pp. 239-248). Chichester, West Sussex, England: Wiley.

Harmison, R. J. (2011). Peak performance in sport: Identifying ideal performance states and developing athletes’ psychological skills. Sport, Exercise, and Performance Psychology, 1, 3-18. doi:10.1037/2157-3905.1.S.3

Heazlewood, I., \& Burke, S. (2011). Self-efficacy and its relationship to selected sport psychological constructs in the prediction of performance in ironman triathlon. Journal of Human Sport and Exercise, 6, 328-350. doi:10.4100/jhse.2011.62.14

Krane, V., \& Williams, J. M. (2006). Psychological characteristics of peak performance. In J. M. Williams (Eds.), Applied sport psychology: Personal growth to peak performance (pp. 207-227). New York, NY: McGraw-Hill.

Lonsdale, C., Hodge, K., \& Rose, E. A. (2008). The Behavioural Regulation in Sport Questionnaire (BRSQ): Instrument development and initial validity evidence. Journal of Sport and Exercise Psychology, 30, 323-355.

Mallett, C. J., \& Hanrahan, S. J. (2004). Elite athletes: Why does the 'fire' burn so brightly? Psychology of Sport and Exercise, 5, 183-200. doi:10.1016/S1469- 
549

550

551

552

553

554

555

556

557

558

559

560

561

562

563

564

565

566

567

568

569

570

571

572

Marcora, S. (2009). Perception of effort during exercise is independent of afferent feedback from skeletal muscles, heart, and lungs. Journal of Applied Physiology, 106, 2060-2062. doi:10.1152/japplphysiol.90378.2008

Martens, R., Vealey, R. S., Burton, D., Bump, L., \& Smith, D. E. (1990). Development and validation of the competitive sports anxiety inventory 2. In R. Martens, R. S. Vealey, \& D. Burton (Eds.), Competitive anxiety in sport (pp. 117-178). Champaign, IL: Human Kinetics.

Martindale, R., Collins, D., \& Daubney, J. (2005). Talent development: A guide for practice and research within sport. Quest, 57, 353-375. doi:10.1080/00336297.2005 .10491862

McCormack, H. M., Horne, D. J., \& Sheather, S. (1988). Clinical applications of visual analogue scales: A critical review. Psychological Medicine, 18, 1007-1019.

McNair, D. M., Lorr, M., \& Droppleman, L. F. (1992). Revised manual for the profile of mood states. San Diego, CA: Educational and Industrial Testing Services.

Morgan, W. P. (1997). Mind games: The psychology of sport. In D. R. Lamb \& R. Murray (Eds.), Perspectives in exercise science and sports medicine: Optimizing sport performance (Vol. 10, pp. 1-62). Carmel, IN: Cooper Publishing Company.

Mujika, I. (2011). Tapering for triathlon competition. Journal of Human Sport and Exercise, 6, 264-270. doi:10.4100/jhse.2011.62.06

Nezhad, M. A. H., \& Sani, K. D. (2012). The effect of intrinsic motivation and sport commitment on the performance of Iranian national water polo team. International Research Journal of Applied and Basic Sciences, 3, 1173-1177.

Rasbash, J., Steele, F., Browne, W. J., \& Goldstein, H. (2012). A user's guide to MLwiN: Version 2.26. London, UK: Institute of Education, University of London. 
573 Robazza, C., Pellizzari, M., \& Hanin, Y. (2004). Emotion self-regulation and athletic

574

575

576

577

578

579

580

581

582

583

584

585

586

587

588

589

590

591

592

593

594

595

596

597

598

performance: An application of the IZOF model. Psychology of Sport and Exercise, 5, 379-404. doi:10.1016/S1469-0292(03)00034-7

Ryan, R. M., \& Deci, E. L. (2007). Active human nature: Self-determination theory and the promotion and maintenance of sport, exercise, and health. In M. S. Hagger, \& N. L. D. Chatzisarantis (Eds.), Intrinsic motivation and self-determination in exercise and sport (pp. 1-19). Champaign, IL: Human Kinetics.

Schwanhausser, L. (2009). Application of the Mindfulness-Acceptance-Commitment (MAC) protocol with an adolescent springboard diver. Journal of Clinical Sports Psychology, 4, 377-395.

Swain, A. B. J., \& Jones, G. (1993). Intensity and frequency dimensions of competitive state anxiety. Journal of Sport Sciences, 11, 533-542. doi:10.1080/02640419308730024

Thelwell, R. C., Greenlees, I. A., \& Weston, N. J. V. (2006). Using psychological skills training to develop soccer performance. Journal of Applied Sport Psychology, 18, 254-270. doi:10.1080/10413200600830323

Thomas, P. R., Murphy, S. M., \& Hardy, L. (1999). Test of performance strategies: Development and preliminary validation of a comprehensive measures of athletes’ psychological skills. Journal of Sport Sciences, 17, 697-711. doi:10.1080/026404199365560

Vlachopoulos, S. P., Karageorghis, C. I., \& Terry, P. C. (2000). Motivation profiles in sport: A self-determination theory perspective. Research Quarterly for Exercise and Sport, 71, 387-397.

Wiggins, M. S. (1998). Anxiety intensity and direction: Preperformance and temporal patterns and expectations in athletes. Journal of Applied Sport Psychology, 10, 201211. 
Table 1

Means and Standard Deviations for all Variables at all Time Points

\begin{tabular}{|c|c|c|c|c|c|c|c|c|c|c|c|c|c|c|c|c|c|c|}
\hline \multirow[b]{2}{*}{ Variable } & \multirow[b]{2}{*}{ ICC } & \multirow[b]{2}{*}{$\alpha$} & \multicolumn{2}{|c|}{14 days } & \multicolumn{2}{|c|}{12 days } & \multicolumn{2}{|c|}{10 days } & \multicolumn{2}{|c|}{8 days } & \multicolumn{2}{|c|}{6 days } & \multicolumn{2}{|c|}{4 days } & \multicolumn{2}{|c|}{2 days } & \multicolumn{2}{|c|}{ Morning } \\
\hline & & & $M$ & $S D$ & $M$ & $S D$ & $M$ & $S D$ & $M$ & $S D$ & $M$ & $S D$ & $M$ & $S D$ & $M$ & $S D$ & $M$ & $S D$ \\
\hline Autonomous & .84 & .67 & 5.06 & 1.10 & 4.94 & 1.13 & 4.99 & 1.09 & 4.96 & 1.06 & 5.02 & 1.19 & 5.12 & 1.12 & 5.05 & 1.10 & 5.01 & 1.13 \\
\hline \multicolumn{19}{|l|}{ Motivation } \\
\hline Self- & .68 & .80 & 3.03 & .59 & 3.02 & .67 & 3.00 & .65 & 3.08 & .65 & 3.14 & .03 & 3.11 & .66 & 3.19 & .66 & 3.04 & .87 \\
\hline \multicolumn{19}{|l|}{ efficacy } \\
\hline Mental & .76 & .70 & 3.40 & .52 & 3.42 & .65 & 3.43 & .54 & 3.37 & .54 & 3.36 & .59 & 3.37 & .59 & 3.61 & 1.03 & 3.49 & .56 \\
\hline \multicolumn{19}{|l|}{ Skills Use } \\
\hline Social & .88 & .86 & 3.35 & .71 & 3.33 & .73 & 3.30 & .79 & 3.30 & .78 & 3.30 & .81 & 3.39 & .73 & 3.38 & .78 & 3.30 & .90 \\
\hline \multicolumn{19}{|l|}{ Support } \\
\hline Perceptions & .47 & .85 & 2.30 & .97 & 2.25 & .9 & 2.55 & .78 & 2.55 & 1.05 & 2.38 & 1.05 & 2.18 & .92 & 1.99 & 1.09 & 1.97 & 1.97 \\
\hline of Fatigue & & & & & & & & & & & & & & & & & & \\
\hline
\end{tabular}

Note. ICC $=$ Intraclass Correlation Coefficients, $\alpha=$ median Cronbach's alpha coefficients over the eight measurement occasions 
Table 2

Final Unconditional Growth Models Describing Changes in Study Variables over the Eight Measurement Occasions

\begin{tabular}{|c|c|c|c|c|c|c|}
\hline \multirow[b]{2}{*}{ Model } & & \multicolumn{5}{|c|}{ Outcome Variable } \\
\hline & & $\begin{array}{l}\text { Autonomous } \\
\text { Motivation }\end{array}$ & Self-efficacy & Mental Skills Use & Social Support & $\begin{array}{l}\text { Perceptions of } \\
\text { Fatigue }\end{array}$ \\
\hline Unconditional & Intercept & $5.010^{* *}$ & $3.073^{* *}$ & $3.509 * *$ & $3.326 * *$ & $1.969 * *$ \\
\hline & Quadratic Time & $-0.050 *$ & $-0.041^{*}$ & 0.026 & $-0.031 * *$ & -0.009 \\
\hline & Cubic Time & $0.005 *$ & $0.004^{*}$ & $-0.002 *$ & $0.003^{* *}$ & -0.001 \\
\hline Between-Person & Intercept & $1.119 * *$ & $0.487 * *$ & $0.231 * *$ & $0.652 * *$ & $1.588 * *$ \\
\hline
\end{tabular}


Table 3

Final Conditional Growth Models Describing Changes in Study Variables over the Eight Measurement Occasions

\begin{tabular}{|c|c|c|c|c|c|c|}
\hline \multirow[b]{2}{*}{ Model } & & \multicolumn{5}{|c|}{ Outcome Variable } \\
\hline & & $\begin{array}{c}\text { Autonomous } \\
\text { Motivation }\end{array}$ & Self-efficacy & Mental Skills Use & Social Support & $\begin{array}{c}\text { Perceptions of } \\
\text { Fatigue }\end{array}$ \\
\hline Conditional & Intercept & $5.010 * *$ & $3.073 * *$ & $3.509 * *$ & $3.326 * *$ & $1.969 * *$ \\
\hline Growth Model for & Linear time & 0.116 & 0.100 & $-0.110^{*}$ & 0.069 & 0.158 \\
\hline Normative & Quadratic time & $-0.050 *$ & $-0.041^{*}$ & 0.026 & $-0.031 * *$ & -0.009 \\
\hline \multirow[t]{5}{*}{ Performance } & Cubic time & $0.005^{*}$ & $0.004^{*}$ & $-0.002 *$ & $0.003^{* *}$ & -0.001 \\
\hline & Performance & - & - & 0.004 & 0.011 & 0.004 \\
\hline & $\begin{array}{l}\text { Performance } \times \\
\text { Linear time }\end{array}$ & - & - & $-0.001^{*}$ & $-0.001 *$ & $-0.003^{* *}$ \\
\hline & $\begin{array}{l}\text { Performance } \times \\
\text { Quadratic time }\end{array}$ & - & - & - & - & - \\
\hline & $\begin{array}{l}\text { Performance } \times \\
\text { Cubic time }\end{array}$ & - & - & - & - & - \\
\hline Conditional & Intercept & $5.010 * *$ & $3.073 * *$ & $3.517 * *$ & $3.342 * *$ & $1.955^{* *}$ \\
\hline Growth Model for & Linear time & 0.116 & 0.100 & $-0.110 *$ & 0.068 & 0.163 \\
\hline Self-referenced & Quadratic time & $-0.050 *$ & $-0.041^{*}$ & 0.026 & $-0.031 * *$ & -0.009 \\
\hline \multirow[t]{5}{*}{ Performance } & Cubic time & $0.005^{*}$ & $0.004^{*}$ & $-0.002 *$ & $0.003^{* *}$ & -0.001 \\
\hline & Performance & - & - & 0.022 & $-0.042 *$ & 0.040 \\
\hline & $\begin{array}{l}\text { Performance } \times \\
\text { Linear time }\end{array}$ & - & - & - & $0.002^{*}$ & -0.014 \\
\hline & $\begin{array}{l}\text { Performance } \times \\
\text { Quadratic time }\end{array}$ & - & - & - & - & $0.002 *$ \\
\hline & $\begin{array}{l}\text { Performance } \times \\
\text { Cubic time }\end{array}$ & - & - & - & - & - \\
\hline
\end{tabular}

Note. A dashed line indicates that the term was not significant and was, therefore, removed from the final models. ${ }^{*} p<.05$. ${ }^{* *} p<.01$ 
Figure 1. Growth curves for study variables as a function of self-referenced performance.

Figure 2. Growth curves for study variables as a function of normative performance. 
$1 \mathrm{~A}$

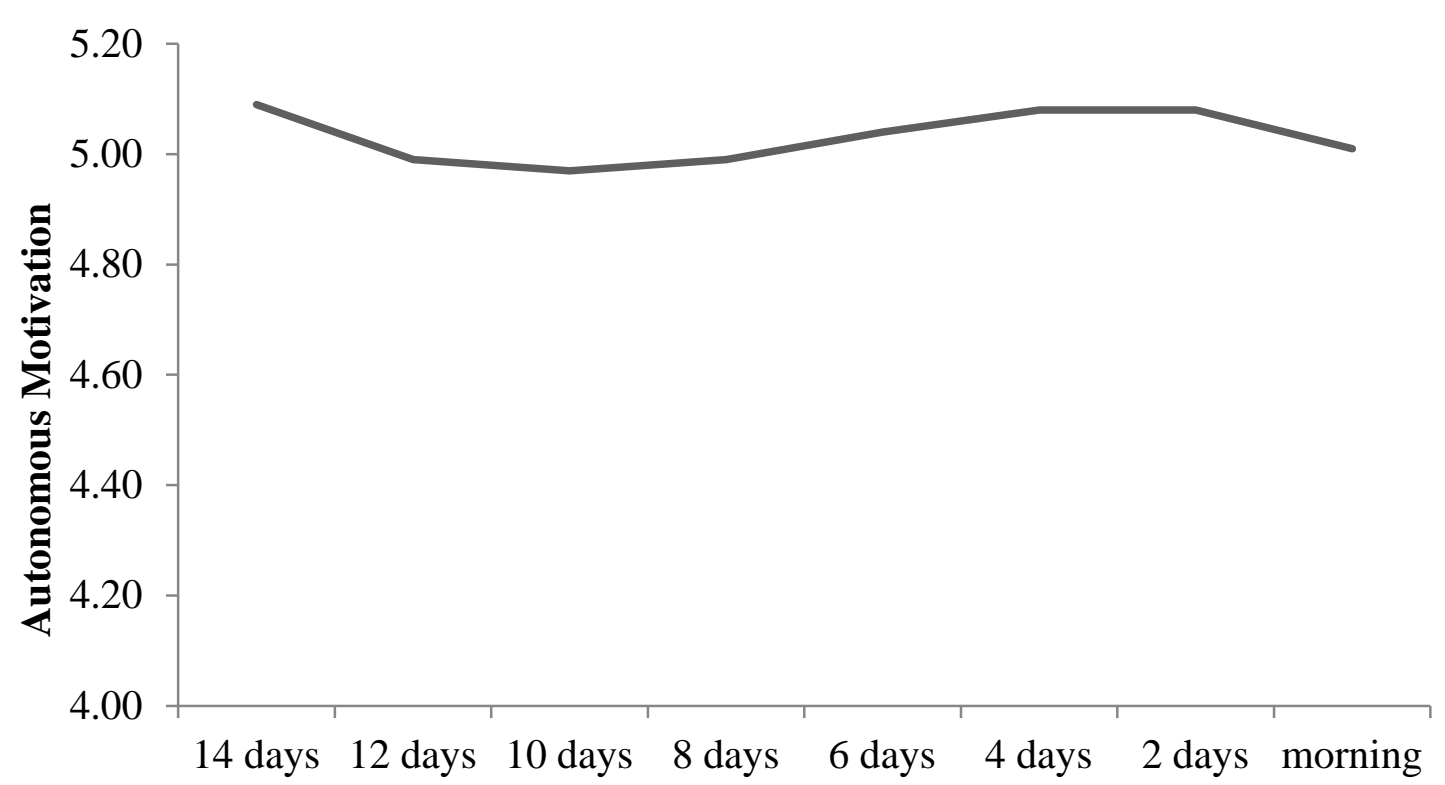

Time Point

$1 \mathrm{~B}$

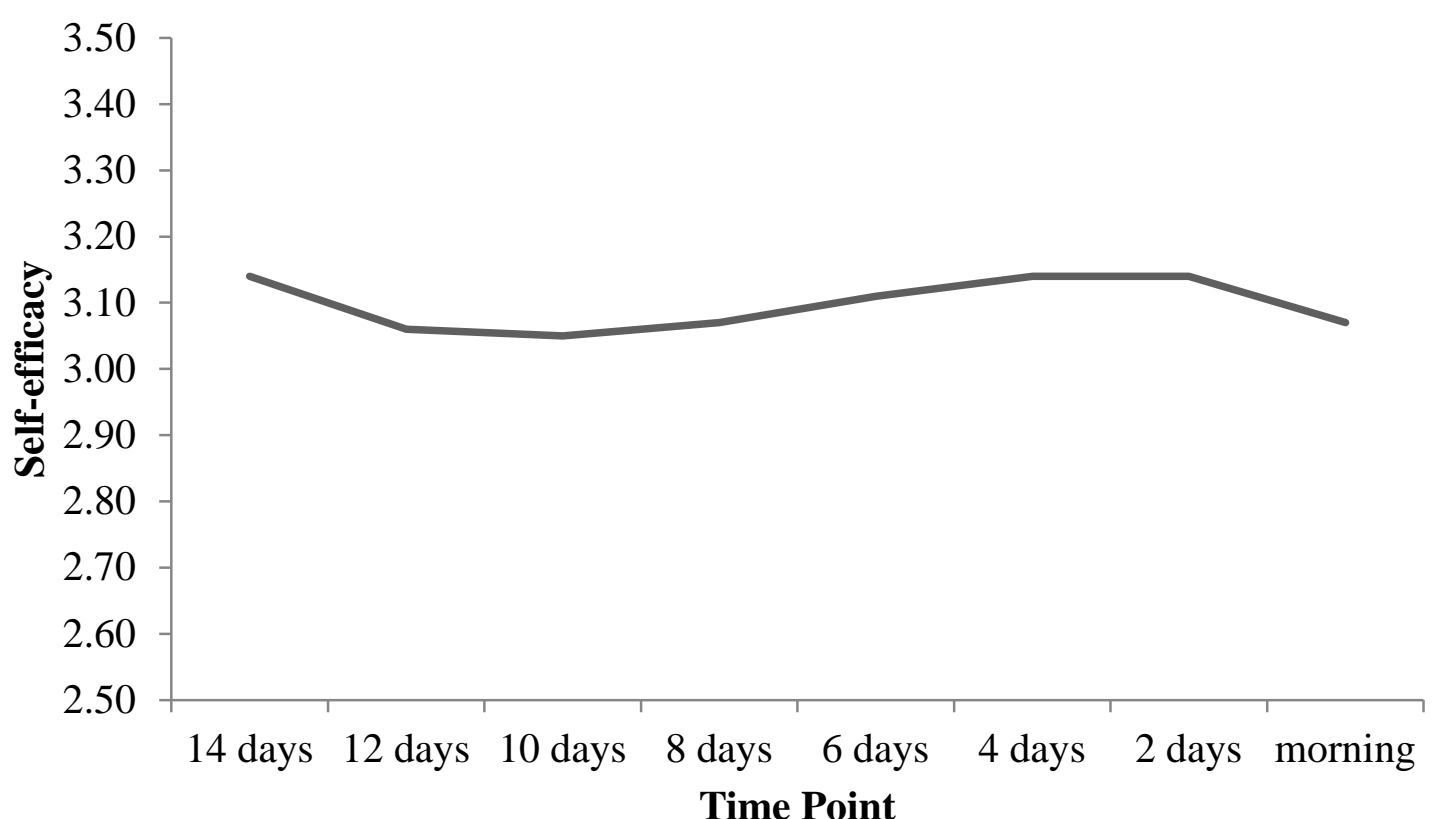

Time Point 


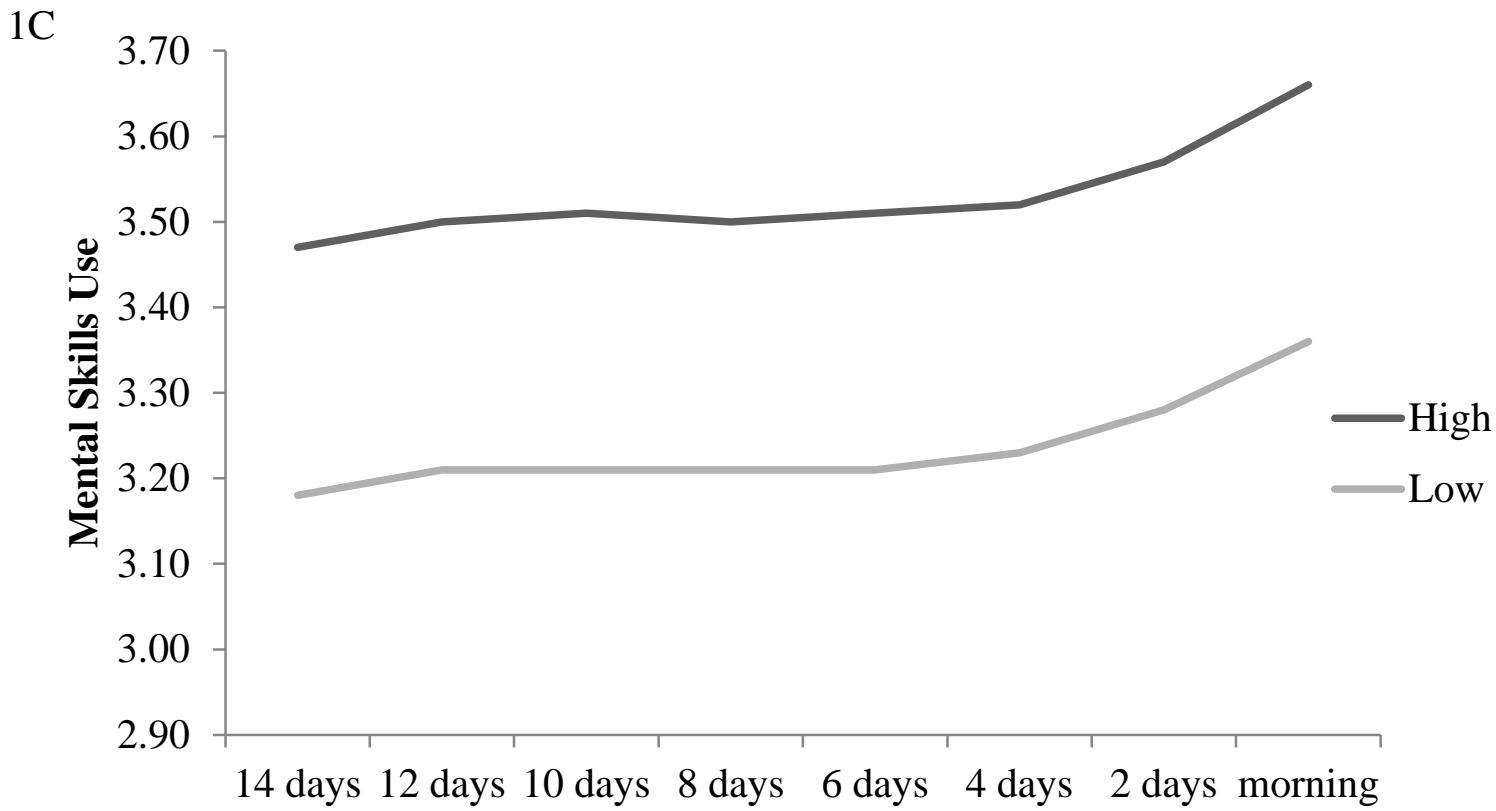

Time Point

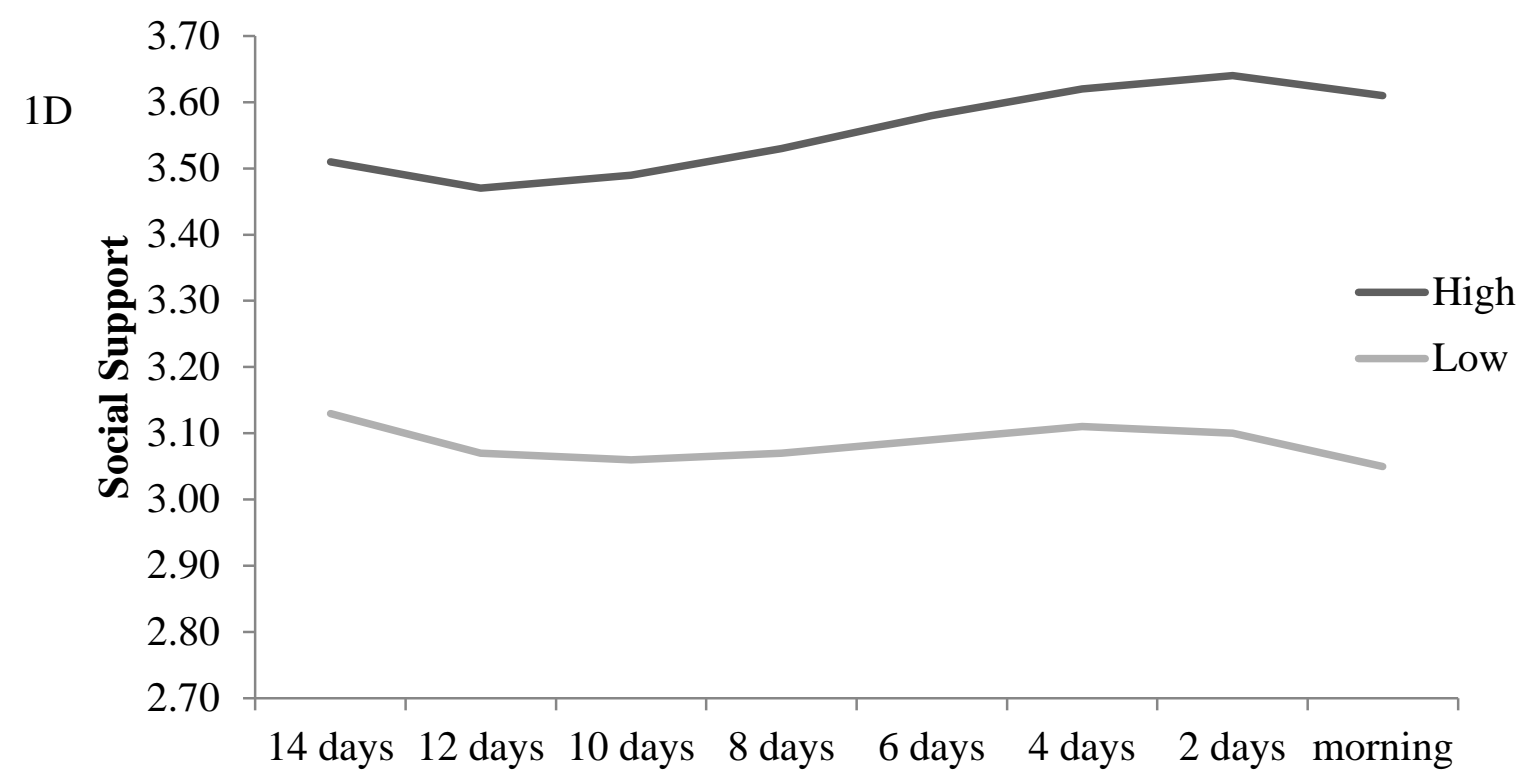

Time Point 


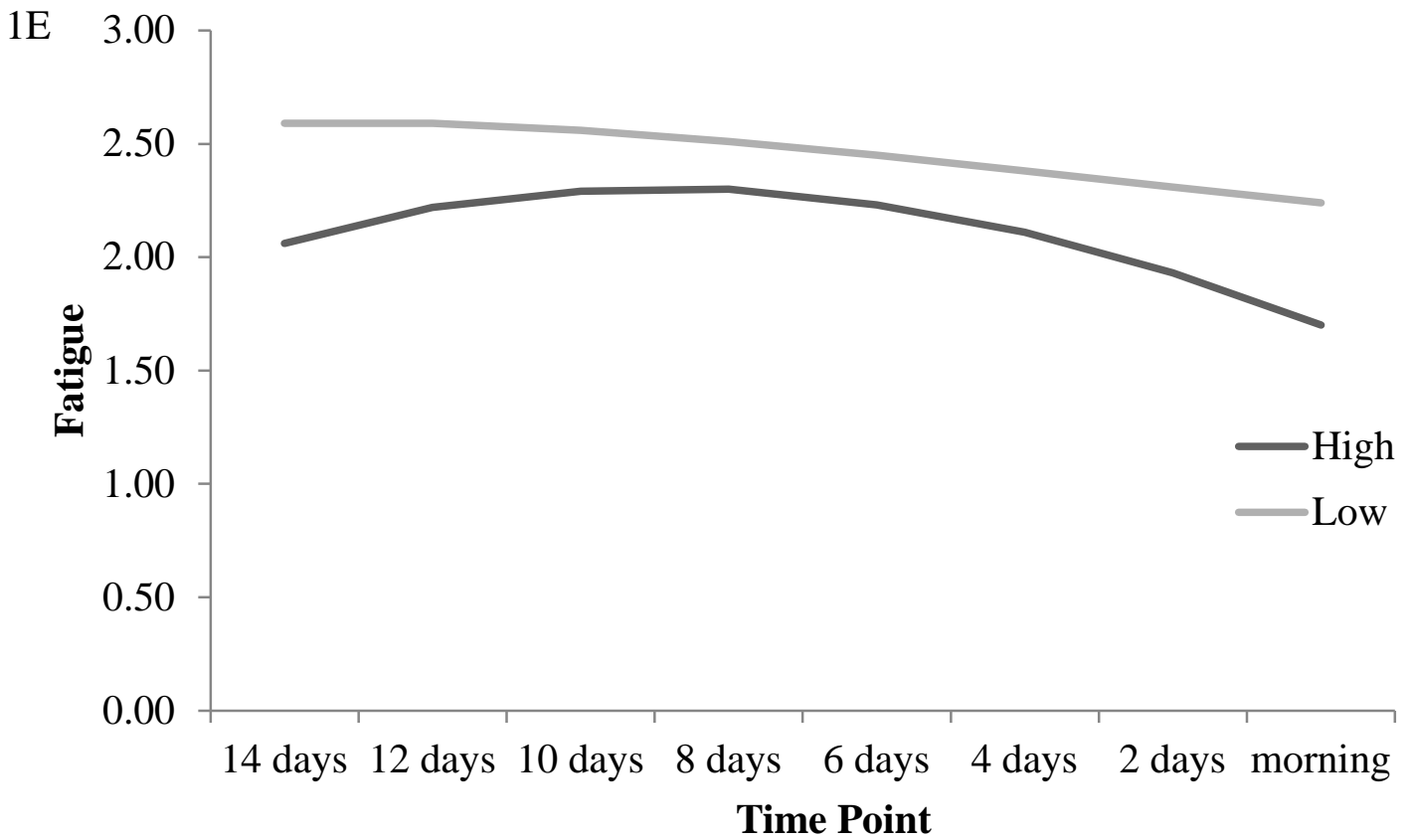

Note. High/Low performance was classified as one standard deviation -/+ mean performance. 
2A

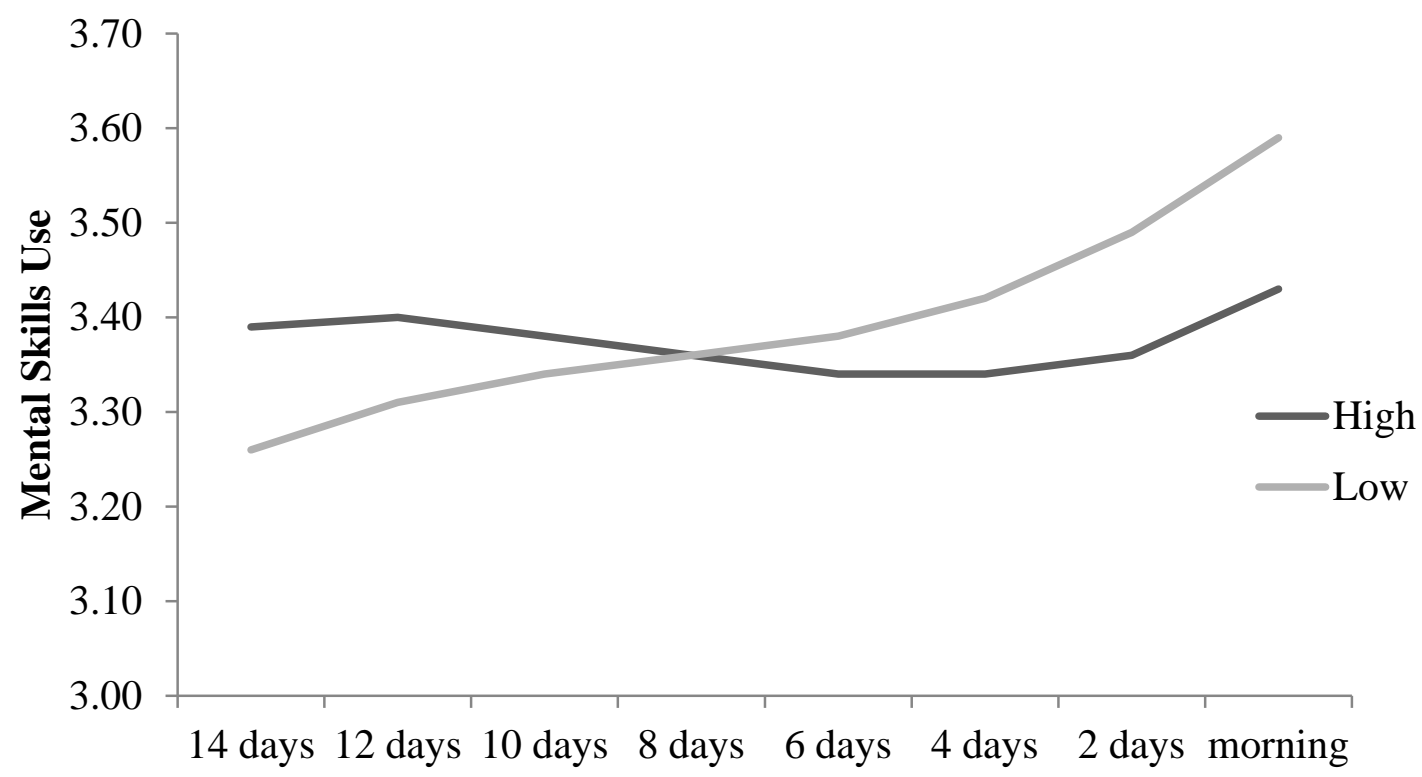

Time Point

2B

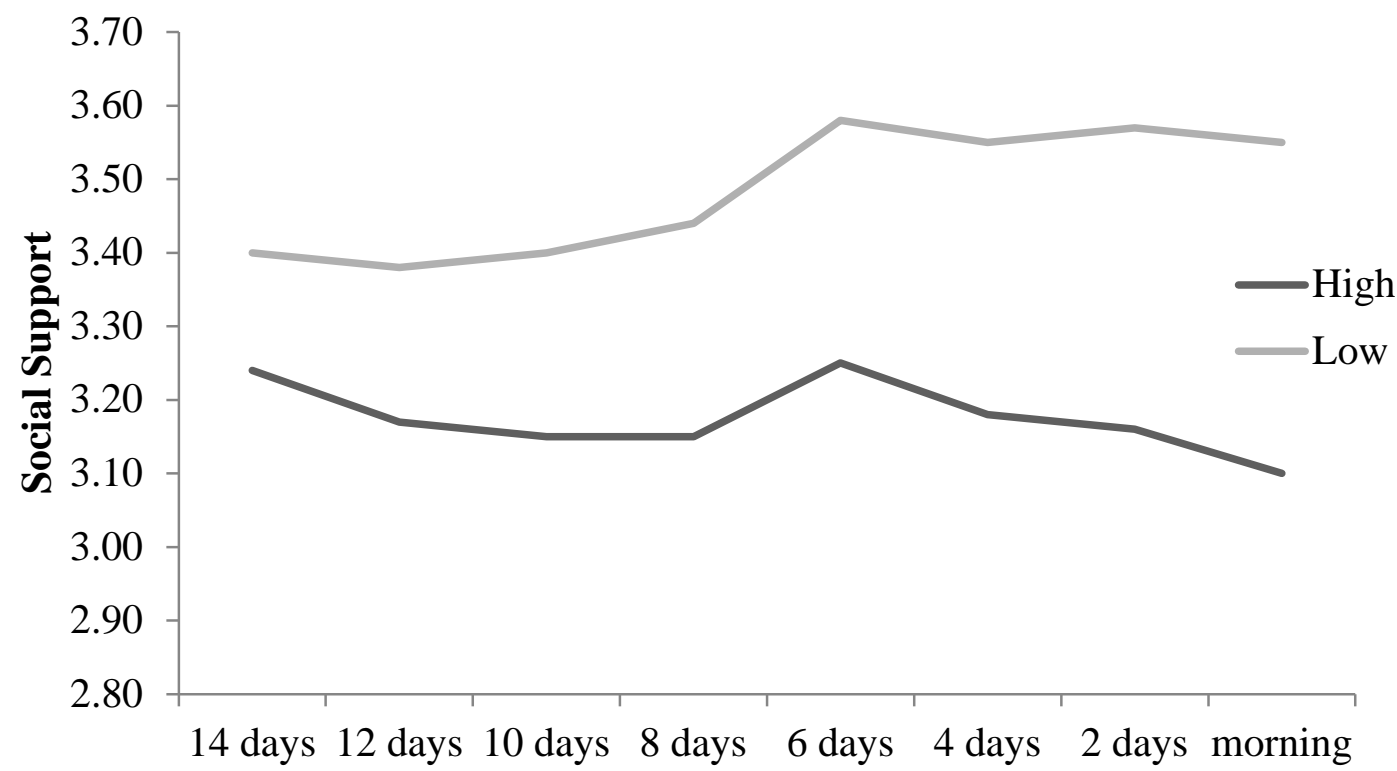

Time Point 


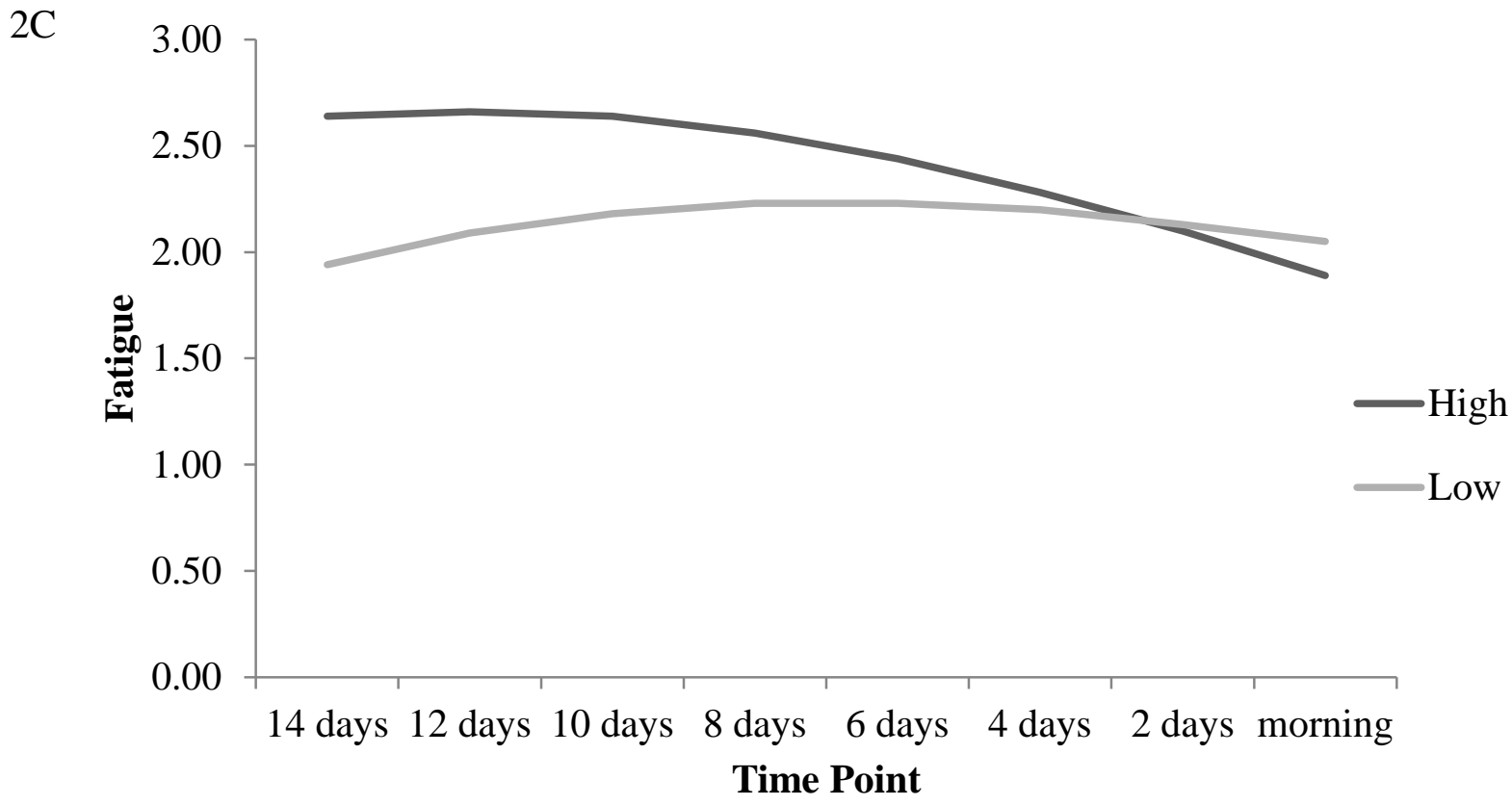

Note. High/Low performance was classified as one standard deviation -/+ mean performance. 